\title{
Análisis de las aplicaciones móviles de destinos turísticos y su accesabilidad
}

\author{
Miguel Ángel Sánchez Jiménez ${ }^{1}$ \\ Rafael Ravina Ripoll ${ }^{2}$
}

Recibido el 5 de marzo de 2017, aprobado para su publicación el 19 de mayo de 2017

\begin{abstract}
Resumen
Los dispositivos móviles se han convertido en un elemento imprescindible en nuestra vida. Este hecho no puede pasar desapercibido por las marcas y los participantes del negocio empresarial, que ven una gran oportunidad para dirigirse a los consumidores, cumpliéndose así una de las máximas del marketing, en el que estos participantes deben estar donde están los consumidores. Esta oportunidad abre un amplio abanico de herramientas y estrategias para relacionarse, comunicarse y ofrecer un mayor valor a los consumidores a través del marketing móvil. En este nuevo concepto de negocio destaca la oferta de destinos turísticos, cuyas características son idóneas para ser tratado en este ámbito. Además, existe una diversidad de grupos sociales que navegan a través de las aplicaciones móviles, entre ellos las personas discapacitadas. Para que una persona discapacitada pueda acceder a los contenidos disponibles en este tipo de plataformas desde un dispositivo móvil, éste tiene que ser accesible. En este artículo consideramos de interés realizar un análisis de las principales aplicaciones móviles de destinos turísticos, tomando como referencia su accesibilidad, comprobando así sus características a través de varios factores.
\end{abstract}

\section{Palabras claves}

Dispositivos móviles, marketing digital, Smartphone, aplicaciones web, aplicaciones nativas, aplicaciones híbridas, geolocalización.

\section{Abstract}

Mobile devices have become an essential element in our life. This fact cannot pass unperceived by company business trademarks and their

1. Miguel Ángel, Personal Docente e Investigador, Depto. de Marketing y Comunicación Universidad de Cádiz. miguelangel.sanchez@uca.es

2. Máster en Administración y Dirección de Empresas, Universidad de Cádiz. rafael.ravina@uca.es 
participants, they see a great opportunity to focus on the consumers, achieving one of the marketing maxims, where these participants should be where the consumers are. This opportunity opens a wide variety of tools and strategies to connect, communicate and offer a largest value to the consumers through marketing mobile. In this new business concept stands out the importance of the tourist destinations offer, whose characteristics are suitable for treatment in this area. In addition, a variety of social groups navigating through mobile applications, including people with disabilities. For a disabled person to access the content available on these platforms from a mobile device, it has to be accessible. In this article we consider interesting to conduct an analysis of the main tourist destinations mobile applications, with reference to its accessibility and checking their features through various factors.

\section{Keywords}

Mobile devices, digital marketing, smartphone, web applications, native applications, hybrid applications, geolocation.

\section{Introducción}

La creciente importancia de las nuevas tecnologías y el marketing digital hace necesario el estudio del impacto que tendrán estos aspectos en el negocio empresarial, más concretamente en aquellos sectores que son más importantes en nuestro país. El estudio llevado a cabo por Travel\&TourismCompetitivenessRep ort 2015 que realiza anualmente el Foro Económico Mundial especifica que el turismo es el sector más importante en nuestro país y que España cuenta con la economía mejor preparada para el turismo obteniendo el mayor índice de competitividad de viajes y turismo. Además, se especifica que la clave de conseguir el primer puesto este año ha sido el desarrollo digital que ha vivido el sector turístico español, destacando "la habilidad para apoyar digitalmente la búsqueda de entretenimiento" lo cual refleja cómo el país se ha adaptado a los hábitos de consumo llegados con la revolución digital. Dentro del futuro del sector turístico señala la importancia en el desarrollo de las tecnologías de información y comunicación (TIC) como uno de los retos pendientes. Por último, señala la necesidad de que el sector se adapte rápidamente al marketing digital y como Internet en el móvil define cada vez más cómo los viajeros seleccionan, planifican y evalúan sus viajes. Por lo tanto, queda claro que resulta esencial señalar la necesidad de que los países se adapten a las nuevas tendencias del turismo.

Dentro de estas nuevas tecnologías de la comunicación nos vamos a centrar en aquella que se da a través de los nuevos dispositivos móviles inteligentes o Smartphone, en el que el marketing móvil y el uso de aplicaciones móviles han cobrado una gran importancia en estos últimos años. El VI Estudio Anual del 
Mobile Marketing realizado por IABSpain resalta esta importancia del marketing móvil, en el que la inversión en este ámbito ha crecido una media del 65\% anualmente. Además, resalta otros puntos que hacen denotar la necesidad de tener en cuenta el concepto móvil: La alta penetración de estos dispositivos (alcanzando actualmente el $87 \%$ de personas con un Smartphone), el gran aumento del tiempo medio de conexión a través de estos dispositivos, el mayor uso de estos dispositivos en detrimento de otros más tradicionales como el ordenador de sobremesa o portátiles, el uso del móvil en el proceso de decisión de compra, el aumento de la presencia de las marcas y el aspecto que más nos interesa en este estudio en el cuál los productos y servicios más buscados a través de los dispositivos móviles son referidos al ocio y a viajes, lo cual vuelve a destacar la importancia que tiene esta nueva tecnología en el sector turístico.

Dentro de la oferta turística, en este trabajo nos vamos a centrar en los destinos turísticos. Bigné et al (2000) definen el destino turístico como un área que presenta características reconocidas por los visitantes potenciales, las cuales justifican su consideración como entidad y atraen viajes al mismo, con independencia de las atracciones que existan en otras zonas. Se indica que el destino turístico va a depender del número de recursos concentrados, el posicionamiento del destino (su imagen respecto a otros destinos competidores) y el comportamiento de los propios turistas. El marketing puede definirse como el proceso social y de gestión a través del cual los individuos y los grupos obtienen lo que necesitan y desean, mediante la creación e intercambio de productos y valor con otros. De esta manera el marketing de destinos turísticos se basa en satisfacer las necesidades del turista (consumidor turístico) considerando el bienestar y los intereses a largo plazo tanto de los propios turistas como de la localidad local, mejorando su calidad de vida. De esta manera multitud de destinos turísticos compiten para atraer y satisfacer a consumidores turísticos.

Según la investigación llevada a cabo en el año 2013 por la Universidad Pompeu Fabra de Barcelona, los destinos turísticos han tenido que adaptarse a las nuevas tecnologías de la comunicación que han ido surgiendo y que han afectado al marketing de dichos destinos. El primer gran cambio sucedió con la aparición de la Web, más tarde con la utilización de las redes sociales y en la actualidad con las aplicaciones en dispositivos móviles. Esta adaptación se ha ido llevando a cabo en un proceso de prueba y error, en el que iniciativas pioneras han servido como lección a los demás competidores. De esta manera resulta muy útil para el sector conocer que tipos de iniciativas se están llevando a cabo y como se están desarrollando.

\section{Objetivos}

Los objetivos del presente estudio son:

- Realizar una revisión bibliográfica acerca del empleo de las aplicaciones móviles y la accesibilidad en el sector turístico. 
- Analizar las aplicaciones móviles de destinos turísticos españoles y comprobar cómo es su accesibilidad, estudiando sus características principales y las prestaciones ofrecidas al usuario a través de 15 factores que se consideran relevantes para su tratamiento.

\section{Las aplicaciones móviles}

Como hemos comentado antes, actualmente podemos afirmar que el acceso desde el Smartphone está superando a otros medios más tradicionales como el ordenador de sobremesa o los portátiles. Para acceder al contenido del Smartphone debemos destacar que las aplicaciones móviles (apps) son el principal punto de acceso a la información por parte de los usuarios, tal y como detalla el informe publicado por ComScore (2014). Dicho estudio recoge como los usuarios ya destinan el $60 \%$ de su tiempo online a estos dispositivos y de dicho tiempo, un $51 \%$ de este, lo utilizan dentro de aplicaciones móviles.

De esta manera, esta consolidación de las apps como la principal vía de acceso a Internet a través de dispositivos móviles demuestra su gran importancia en el marketing móvil. Consolidación gracias a un cambio de comportamiento liderado por los jóvenes menores de 45 años (Arroyo-Vázquez, 2012). El comportamiento medio del usuario español se caracteriza por un acceso diario de más de dos horas y media y con una utilización del móvil de más de 150 veces al día.

Dentro del $5^{\circ}$ informe de las apps en España (App Date, 2014) nos encontramos con que el usuario medio de las aplicaciones tiene entre 25 y 40 años, usa sus aplicaciones favoritas más de una vez al día y tiene instaladas más de 39 apps de media en su Smartphone. Además, en general existen 23 millones de usuarios activos de apps y se descargan más de 3,8 millones de aplicaciones al día.

Desde el punto de vista económico vamos a tomar como referencia el informe de Visión Mobile (2014) en el cuál se especifica que el negocio de las apps generó 19.300 millones de euros en el 2013. Además, en el mismo año se invirtió más de 110 millones de euros en España, generando este nuevo sector más de 1 millón de puestos de trabajo en 2013 en la UE. De esta manera, desde su aparición en el año 2007 la economía de aplicaciones ha experimentado un gran crecimiento y ha tenido un profundo impacto en la manera en que las personas usan los teléfonos móviles. Asimismo, el gran impulso final para el móvil y las aplicaciones fue el lanzamiento en el 2008 de las tiendas de aplicaciones, propulsada por los Smartphones (cada vez más potentes) y posteriormente con las tablets en 2010. (Vision Mobile, 2014).

En el 2007 aparecieron las aplicaciones con los Smartphones, cuyo pionero fue iPhone de la marca Apple, hecho que revolucionó la telefonía móvil y por tanto el de las propias aplicaciones (Montaner Barrio, 2013), desde entonces se ha producido un gran crecimiento que continua actualmente. 
Una vez destacado la importancia de nuestro objeto principal de estudio para este trabajo definiremos el concepto de aplicación móvil. Para ello tomaremos varias definiciones provenientes de la revisión bibliográfica. La Mobile Marketing Association (MMA, 2012), nos define una aplicación móvil como "un soporte en sí mismo para comunicar, impactar, relacionarse, intercambiar y comerciar desde el punto de vista de Marketing; ofrecen un importante servicio de valor añadido al usuario". Por otro lado, The App Date (2014) define una app como "aquella herramienta que da un uso concreto sobre una amplia variedad de temas a un dispositivo electrónico". De esta manera, su capacidad para adaptarse a los distintos tipos de dispositivos, ya sean Smartphone, tabletas, ordenadores, televisores, electrodomésticos, vehículos y otros aparatos tecnológicos en pleno desarrollo, permite ampliar los servicios o contenidos para el usuario. Otros autores como Arroyo-Vázquez (2013) definen una app como programas que se instalan en nuestro dispositivo móvil y amplían así sus funciones. Montaner (2013) completa esta definición añadiendo que una app debe ser descargada e instalada en el móvil (normalmente desde una tienda virtual, como AppStore o Google Play). Según Lara-Navarra et al (2014) las apps son un elemento clave de valor añadido que nos permiten comunicar, impactar, intercambiar y fidelizar al usuario a través de su uso, dado que son capaces de dar respuesta inmediata y de forma personalizada cumpliendo los criterios de información ubicua, en cualquier lugar, a cualquier hora y a medida. En este mismo artículo, se considera que la aceptación de estas aplicaciones puede atribuirse a tres grandes cambios. Por un lado, apremian la evolución del propio concepto de teléfono, atribuyéndole utilidades más allá de las simples llamadas telefónicas. Por otro lado, destacan la facilidad de uso de las aplicaciones móviles, caracterizándolas como fáciles de usar, cargar o borrar. Lara-Navarra (2014) cita textualmente "se han eliminado los engorrosos procesos de descargar aplicaciones a partir de conectar el móvil al ordenador para ejecutar los CD o procesos similares, ahora existen mercados propios de aplicaciones como Play Store de Google o la App Store de Apple, que han facilitado el acceso de forma ordenada a la aplicación que necesitas". En tercer lugar, hay que destacar el mercado de creación de aplicaciones móviles, y su capacidad de poder llegar a cualquier usuario mundial. (Lara-Navarra, 2014).

En resumen, podemos considerar una aplicación móvil como es un software que se ejecuta en un dispositivo móvil (smartphone y tablets) y desarrolla ciertas tareas para el usuario, convirtiendo los Smartphone en un dispositivo intuitivo, potente, táctil y siempre online. Desde una visión de marketing las aplicaciones móviles pueden considerarse soportes para comunicar, publicitarse, impactar, relacionarse, intercambiar y comercializar, lo cual proporcionaría un valor añadido, cubriendo las necesidades de los consumidores de manera inmediata y personalizada. De esta manera, y tal como comenta Bruno Ramos (2014), las aplicaciones móviles se han convertido en el complemento ideal de cualquier estrategia de Mobile Marketing corporativa. 
Dentro del concepto de aplicación móvil cabe destacar la existencia de las tiendas de aplicaciones. Teniendo en cuenta a Kim et al (2012) una tienda de aplicaciones es un mercado único y organizado donde la adquisición de aplicaciones se realiza de forma transparente, fiable y directa. La distribución de aplicaciones móviles en tiendas de aplicaciones por sistema operativo se inició con Apple en julio de 2008 con el lanzamiento de su tienda de aplicaciones llamada Apple Store, dentro de su sistema operativo iOS. Dicha plataforma esta oficialmente restringida dependiendo de la validación por parte de Apple para que una aplicación pueda ser lanzada. Tras el éxito de Apple Store, otros fabricantes de Smartphones lanzaron sus propias tiendas de aplicaciones móviles, apareciendo así otras plataformas en la que destaca principalmente el sistema operativo Android y su tienda de aplicaciones Google Play. Todo esto junto a la aparición de las tablets, la mayor gama de smartphone y bajada de precio de la tarifa de navegación por parte de las operadoras ha propiciado un aumento de consumo de aplicaciones entre los usuarios.

Un punto importante a tener en cuenta en la tienda de aplicaciones móviles y que afectará al actual ámbito de estudio es el posicionamiento natural en la tienda de aplicaciones o App Store Optimization (ASO). Según IAB Spain (2014) ASO es el proceso de optimización de una aplicación móvil con el fin de conseguir aparecer en los primeros resultados cuando los usuarios buscan en las tiendas de aplicaciones. Es el SEO de las aplicaciones móviles. Varios son los factores que intervienen en el ASO y por lo tanto que una aplicación se encuentre mejor situada en la tienda, vamos resumirlo teniendo en cuenta aquellos factores internos y factores externos:

- Factores internos:

- Titulo (App Name)

- Descripción

- Keywords (Palabras Clave)

- Categoría de la app

- Icono y screenshots (capturas de pantalla)

- Video

- Factores externos:

- Instalaciones vs Desinstalaciones

- Valoraciones y reviews de usuarios en el market

- Reviews en sitios web o blogs especializados

- Comentarios en Social Media

Una vez visto el concepto de las aplicaciones móviles vamos a ver de manera sintetizada la clasificación que podemos hacer de las aplicaciones móviles, ya que servirá para comprender mejor el objeto de este trabajo. Teniendo en cuenta obras como las de Hernández (2014), Delía et al (2013) y Estrade et al (2013) podemos considerar tres tipos de clasificaciones en las aplicaciones 
móviles: Una referida a las funcionalidades que estas aportan al usuario, otra según el entorno en el que se ejecutan y la tercera referida a la monetización de la aplicación, veamos cada una de ellas. La primera de ellas, referido a las funcionalidades que aportan las aplicaciones, nos encontramos con tipos de aplicaciones según la función que realicen, de esta manera nos podemos encontrar con aplicaciones de juegos, productividad, multimedia, utilidades, bienestar, etc., destacando entre todas ellas aquella que es objeto de nuestro estudio, la referida a los viajes, más concretamente a guías de destinos turísticos. La segunda clasificación, referida al entorno de ejecución, aclara que las aplicaciones pueden dividirse entre aplicaciones web, aplicaciones nativas o aplicaciones hibridas. Resumiremos los aspectos esenciales de cada una de ellas:

- Aplicaciones web: Se desarrollan por lenguajes conocidos de programación como es el HTML, Javascript y CSS (Navarra y Maniega, 2014). Se ejecutan dentro del propio navegador web del dispositivo a través de una URL y sólo funcionan con conexión a internet. No necesita instalación por lo que no pueden estar visibles en las tiendas de aplicaciones (sólo a través de acceso directo).

- Aplicaciones nativas: Funcionan en sistemas operativos móviles nativos como iOS, Android, Windows mobile, Blackberry, Symbian, etc. , por lo tanto, es necesario conocimientos de desarrollo informático para crearlas (Delía, et al, 2013). La descarga e instalación de estas apps se realiza siempre a través de las tiendas de aplicaciones. Se puede acceder a sus contenidos sin acceso a internet. Acceso a todas las características del dispositivo: cámara, GPS, agenda, dispositivos de almacenamiento, etc., que se traduce en una mejor experiencia. Permite el envío de notificaciones o avisos a los usuarios. Dentro de las características de las aplicaciones nativas, podemos encontrarnos, por ejemplo, las que necesitan frecuentes actualizaciones, las cuales a veces corrige errores o añade mejoras. Asimismo, a nivel de diseño, esta clase de aplicaciones tiene una interfaz que logra mayor coherencia y consistencia con el resto de aplicaciones y con el propio sistema operativo. Lo que favorece la usabilidad. (Cuello y Vittone, 2013).

- Aplicaciones hibridas: Es un intermedio de las anteriores, buscando aprovechar lo mejor de ambas. Se desarrollan con lenguajes propios de las aplicaciones Web (HTML, Javascript y CSS). Conllevan la posibilidad de acceder a parte de las características y elementos del dispositivo y además es posible distribuirlas en las tiendas de aplicaciones (Estrade et al, 2013). Como inconveniente presenta que no tiene acceso a la totalidad de las características del dispositivo y sus posibilidades de diseño es algo más limitado.

En lo que nos respecta a nuestro ámbito de estudio, nos centraremos en aquellas aplicaciones, ya sean nativas o hibridas, que pueden descargarse a través de la tienda de aplicaciones. 
Por último, la tercera clasificación es otro aspecto que tendremos en cuenta en este estudio, y es el tipo de aplicación teniendo en cuenta el beneficio monetario obtenido (Liberos et al, 2013). En este caso podemos dividir las aplicaciones en:

- Aplicaciones de pago.

- Aplicaciones gratuitas.

- Aplicaciones gratuitas con anuncios.

- Aplicaciones gratuitas + pago por contenidos adicionales.

Destacar también la existencia de dos modelos de negocio en las aplicaciones (Richardson, 2014), uno basado en una propuesta comercial, ya sea de funcionalidades de la propia aplicación, contenidos, compra-venta de productos y servicios, etc., y otro basado en el uso de las aplicaciones como vehículos conductores de comunicación y promoción, permitiendo establecer comunicaciones y relaciones con los usuarios, ganando presencia y notoriedad para la marca o el negocio. Es este último al cual nos referiremos en este artículo, tomando aplicaciones de guías de destinos turísticos.

Dos aspectos a tener en cuenta en las aplicaciones móviles son su diseño y su usabilidad, dos aspectos que están interrelacionados. Hassan et al (2004) considera que un diseño atractivo y estético es lo primero que llama la atención del usuario y puede conseguir que siga navegando. Según Nielsen y Loranger (2006) la usabilidad puede definirse como la facilidad de uso, más específicamente, hace referencia a la rapidez con que se puede aprender a utilizar algo, la eficiencia al utilizarlo, cuál es su grado de propensión al error, y cuánto les gusta a los usuarios. Si una característica no se puede utilizar o no se utiliza, es como si no existiera. Sánchez (2012) considera la usabilidad en las aplicaciones móviles la navegación por la aplicación, analizada conforme a: presencia de menú de secciones, navegación dentro de la misma sección, claridad en la estructura de navegación, etc. y es un aspecto esencial para la calidad de la aplicación. Estos dos conceptos van unidos a que la información o el contenido que se ofrece sean atractivos. Teniendo en cuenta el estudio de Hassan et al (2004), los factores de calidad de una aplicación o sitio web que influirán en la satisfacción del usuario pueden ser clasificados en aquellos relacionados con: el atractivo o utilidad de los contenidos; la usabilidad y la calidad del diseño de la aplicación.

\section{La accesibilidad en el turismo}

Según Pérez y Velasco (2003), el turismo accesible puede definirse desde sus inicios como aquel que garantiza el uso y disfrute del turismo a las personas que padecen alguna discapacidad física, psíquica o sensorial. Señala que las instituciones nacionales e internacionales han venido trabajando activamente a favor de la promoción de mejores condiciones de vida para estas personas con discapacidad. Entre otros objetivos también se ha tratado la facilitación del acceso a las infraestructuras y servicios turísticos a las personas con discapacidad 
y movilidad reducida (PMR). De esta manera se ha usado el término "Turismo para todos" para denominar aquella forma de turismo que planea, diseña y desarrolla actividades turísticas de ocio y tiempo libre de manera que puedan ser disfrutadas por toda clase de personas con independencia de sus condiciones físicas, sociales o culturales. Por lo tanto, destaca que su finalidad es la plena integración de las PMR al disfrute y acceso a los servicios turísticos, entendidos éstos desde una perspectiva integral (hoteles, restaurantes, recursos turísticos, transporte, etc.). El turismo accesible pretende dar respuesta a todas las recomendaciones, declaraciones, etc. que se centran en la posibilidad de crear una oferta turística dirigida a todos los segmentos de población por igual, sin que se produzca ningún tipo de discriminación.

De forma Similar Rovira-Beleta (2005) define el turismo accesible como "aquel que se ocupa de la problemática de las barreras físicas, psíquicas y sensoriales que todavía hoy se encuentran a la hora de hacer turismo las personas que, de alguna forma, tienen dificultad para desplazarse o comunicarse, factores que comprometen la integración y participación de estos consumidores".

Otro aspecto a destacar es el mencionado por Allés (2009) en el que específica la importancia del turismo accesible para la oferta turística como el sector hotelero, de restauración y los destinos turísticos, objeto de nuestro estudio. De esta manera indica que el turismo accesible está creando una verdadera concienciación en todas las empresas del sector turístico por mejorar la accesibilidad para las personas discapacitadas, no sólo con fines lucrativos sino también sociales.

Desde otro punto de vista, la accesibilidad puede ser estudiada como el acceso hacia un nuevo sistema, dispositivo o tecnología. En este sentido Serrano Mascaraque et al (2009, p.8) define la accesibilidad electrónica como "los productos y servicios electrónicos que pueden ser utilizados por los usuarios con efectividad, eficiencia y satisfacción en un contexto de uso determinado". Por ejemplo: accesibilidad de los equipos informáticos (hardware y software), accesibilidad web, accesibilidad de la televisión digital, accesibilidad de la telefonía móvil, así como otros servicios característicos de la sociedad de la información.

De esta manera es indispensable tratar aspectos de la accesibilidad web, ya que en ella se basa los aspectos esenciales de esta accesibilidad hacia dispositivos tecnológicos. En el estudio de Hassan Montero y Martín Fernández (2003) comentan que el gran crecimiento que ha tenido internet en todos estos años ha generado un cambio radical en cuanto a la facilidad de difusión y disponibilidad de la información, las limitaciones y el mal uso de las publicaciones web están dando lugar a situaciones de dificultad de acceso a la información por parte de aquellos usuarios con discapacidad. Por lo tanto, muchos sitios web presentan numerosas barreras de accesibilidad, por lo que resulta de inmediata necesidad 
la puesta en marcha de medidas que terminen con esta situación. Establecen 4 tipos de limitaciones que pueden impedir el acceso a la información web, estas son: deficiencias visuales, deficiencias auditivas, deficiencias motrices y deficiencias cognitivas y de lenguaje. Estas discapacidades no tienen por qué ser excluyentes entre sí y pueden ser de carácter temporal. Estos autores definen la accesibilidad web como "la posibilidad de que un producto o servicio web pueda ser accedido y usado por el mayor número posible de personas, indiferentemente de las limitaciones propias del individuo o de las derivadas del contexto de uso". Aclara que cuando se refiere a "las limitaciones propias del individuo' no solo engloban aquellas representadas por discapacidades, sino también otras como pueden ser el idioma, conocimientos o experiencia. En el mismo sentido Vanderheiden (2000), aclara que la discapacidad no es el único tipo de limitación que dificulta la accesibilidad de contenidos, no solo existen limitaciones propias del individuo, sino otras derivadas del contexto de uso y del dispositivo de acceso empleado. Por lo tanto, se puede deducir que cualquier producto que sea diseñado atendiendo a limitaciones derivadas de discapacidades individuales, posibilitarán y facilitarán así mismo su acceso por usuarios que, sin padecer estas discapacidades, se encuentren en contextos de uso desfavorables y de equivalente limitación, por lo que el número de usuarios beneficiados de este modo de diseño sería mayor que el representado por usuarios con discapacidad. Henry (2003) y Nielsen (2001) también comentan la relación entre los conceptos de accesibilidad y usabilidad, destacando que la accesibilidad no sólo implica la necesidad de facilitar acceso, sino también la de facilitar el uso. Por lo tanto, un diseño será accesible cuando sea usable para más personas en más situaciones o contextos de uso, posibilitando a todos los usuarios, de forma eficiente y satisfactoria, la realización y consecución de tareas. Una buena usabilidad puede facilitar la accesibilidad (Serrano Mascaraque et al, 2009)

En el estudio de Navarro y Fonseca (2008) comentan que la interacción del usuario con la información también es un eje importante en la accesibilidad web. Así consideran importante estudiar la interacción del usuario con la tecnología para generar nuevos entornos que no solo sean usables y accesibles, sino que, gracias a una experiencia con el usuario, sean satisfactorios.

Martín et al (2012) señala que accesibilidad web está dirigida a lograr una web de todos y para todos, independientemente de las discapacidades permanentes o temporales, los problemas asociados a la edad, las brechas generacionales, las habilidades y preferencias delas personas, la cultura y el nivel educacional alcanzado, etc. También destaca que una mala experiencia del usuario en el entorno web puede tener efectos bastantes negativos y difíciles de revertir.

En nuestro ámbito de estudio, la accesibilidad de dispositivos móviles sigue los mismos principios esenciales que la accesibilidad web, pero teniendo en cuenta las particularidades que ya hemos comentado acerca de los dispositivos móviles. Según la definición de Apple: “Una aplicación es accesible cuando 
todos los elementos de la interfaz de usuario con los que los usuarios pueden interactuar son accesibles. Un elemento de la interfaz de usuario es accesible cuando indica correctamente que es un elemento de accesibilidad". Según González (2013) esta definición se refiere a que los elementos que componen la interfaz del usuario de la aplicación deben ofrecer una determinada información para que los servicios de accesibilidad que funcionan en el sistema operativo o los productos de apoyo (software o hardware), puedan interactuar correctamente y permitan el acceso del usuario al dispositivo. Completando la definición puede decirse que una aplicación es accesible cuando cualquier usuario, independientemente de su diversidad funcional, puede utilizarla en su dispositivo móvil satisfactoriamente con su sistema de acceso habitual.

En el estudio de Rios et al (2012) se especifica que debido al aumento de los teléfonos móviles inteligentes o smartphones hay muchos más grupos sociales que hacen uso de estos, entre ellos las personas discapacitadas. Este grupo social hace un uso intensivo de este tipo de dispositivos ya que les ayudan a superar muchas de las barreras que hay instauradas en la sociedad. Para que una persona discapacitada pueda acceder a los contenidos disponibles en este tipo de plataformas desde un dispositivo móvil, éste tiene que ser accesible. Además, comentan que al hablar de accesibilidad en dispositivos móviles se está haciendo referencia tanto al diseño del dispositivo como a las aplicaciones del mismo, ya que ambos van a permitir que estas personas puedan percibir, entender, navegar e interactuar con el dispositivo sin ningún tipo de barrera. En dicho artículo también se señala los beneficios que puede tener este dispositivo para personas con algún tipo de discapacidad:

- Poder mantenerse siempre conectado con la familia y los amigos.

- Navegar por la Web desde cualquier sitio.

- Acceder a información de interés (el tiempo, calendarios, horario de autobuses y trenes, etc.).

- Funcionalidades GPS (localización, ayuda al desplazamiento, etc.).

Para acabar con este punto es indispensable hacer referencia a W3C. W3C es una comunidad internacional que trabaja ininterrumpidamente en el desarrollo de estándares para asegurar el crecimiento de la Web a largo plazo. A través del grupo de trabajo denominado "Iniciativa de Accesibilidad Web" (WAI), propone por primera vez unas recomendaciones denominadas "Guías de Accesibilidad". Esta comunidad considera que la "accesibilidad móvil" generalmente se refiere a hacer sitios web y aplicaciones más accesibles a las personas con discapacidad cuando están utilizando teléfonos móviles. El trabajo de la WAl en esta área incluye a las personas que utilizan una amplia gama de dispositivos para interactuar con la web: móviles, tablets, televisores y mucho más. De esta manera marcan la existencia de 4 principios de accesibilidad que señalan las directrices y criterios que sientan las bases necesarias para que cualquiera pueda acceder y utilizar un contenido web o una aplicación. Según estos 4 
principios de la accesibilidad el contenido debe ser:

1. Perceptible: La información y componentes del interfaz de usuario deben estar presentables a los usuarios de manera que puedan percibirla correctamente. Tiene en consideración:

- El tamaño de la pantalla.

- El zoom o ampliación.

- El contraste.

2. Operable: Esto significa que el interfaz del usuario y la navegación deben ser operables, es decir, que no pueda requerir interacción que el usuario no pueda realizar. Tiene en consideración:

- Control del teclado para dispositivos con pantalla táctil.

- Touch Tamaño de destino y espaciado.

- Los gestos de pantalla táctil.

- Los gestos de manipulación del dispositivo.

- La colocación de los botones donde son de fácil acceso.

3. Comprensible: Esto significa que los usuarios deben ser capaces de entender la información, así como el funcionamiento de la interfaz de usuario (el contenido o la operación no pueden estar más allá de su comprensión). Tiene en consideración:

- Cambio de orientación de la pantalla (Vertical / Horizontal).

- Disposición Consistente.

- Posicionamiento elementos de página importante antes de la página de desplazamiento.

- Agrupar elementos operables que realizan la misma acción.

- Proporcione la indicación clara de que los elementos son recurribles.

- Proporcionar instrucciones de la pantalla táctil de encargo y los gestos de manipulación del dispositivo.

4. Robustos: El contenido debe ser lo suficientemente robusto para que se pueda interpretar de forma fiable por una amplia variedad de aplicaciones de usuario, incluyendo las ayudas técnicas. Tiene en consideración:

- Configurar el teclado virtual para el tipo de entrada de datos requerida.

- Proporcionar métodos fáciles para la entrada de datos.

- Apoyo a las propiedades características de la plataforma.

Estos 4 principios se tendrán en cuenta en el análisis de las aplicaciones móviles turísticas para comprobar su accesibilidad. 


\section{Objetivo y metodología}

El objetivo es comprobar cuán accesibles son las aplicaciones móviles de guías de destinos turísticos españoles, estudiando sus características principales y las prestaciones ofrecidas al usuario.

La muestra que se analiza está formada por las 20 aplicaciones móviles de destinos turísticos españoles que se encuentran mejor situadas en el buscador de la tienda de aplicaciones, concretamente a través de la Apple Store, del Smartphone IPhone 6. Para ello se buscará en dicha tienda de aplicaciones las palabras claves "guía turismo" y se escogerán las 20 guías de destinos turístico pertenecientes a España mejor situadas (ya sean Comunidades Autónomas, provincias, ciudades o localidades). La mejor situación de estas aplicaciones en la Apple Store se debe al posicionamiento natural en la tienda de aplicaciones (ASO) comentado anteriormente en el punto 3.

El análisis se va a realizar a través de 15 factores que se consideran relevantes para conocer la accesibilidad de una aplicación móvil de destino turístico y han sido tratadas a lo largo de la parte teórica de este artículo. Además, para la elección de variables se han tenido en cuenta los siguientes estudios: Informe de investigación de aplicaciones móviles en destinos turísticos (2013), Estudio de Mercado de Apps Turísticas Segitur (2013), Sánchez (2012) y Martín-Sánchez et al (2012).

A continuación, especificamos cada una de las variables utilizadas:

1. Tipo de destino: Pueden ser Comunidades Autónomas, provincias o localidades.

2. Tipo de aplicación por precio: Puede dividirse en aplicaciones gratuitas, gratuitas con anuncios, gratuitas + pago por contenidos adicionales o de pagos.

3. Tamaño de la aplicación: Espacio en MB que ocupa en el dispositivo.

4. Actualización.: Comprobar su última actualización.

5. Idiomas.

6. Oficialidad de la aplicación: si la aplicación es oficial de dicho destino turístico (proveniente de un estamento público) o no.

7. Puntuación de la aplicación por parte del usuario en la tienda de aplicaciones (en caso de que haya valoraciones).

8. Relación de la aplicación móvil con la web: Si la aplicación o la información de la aplicación tiene espacio Web.

9. Conectividad con redes sociales: Si dichas aplicaciones incluyen enlaces a redes sociales.

10. Interactividad: Oportunidad que tiene el usuario de generar contenido, pudiendo valorar o añadir algún comentario.

11. Funciones de la aplicación: Funciones que poseen las aplicaciones y que buscan ofrecer un mayor valor al consumidor.

12. Mención en la aplicación a la accesibilidad hacia personas discapacitadas: 
Se considera si en la aplicación móvil se hace alguna mención a una mejor accesibilidad a personas con discapacidad.

13. Diseño: Puntuación personal otorgada teniendo en cuenta el atractivo y estética de la aplicación.

14. Usabilidad: Puntuación personal otorgada teniendo en cuenta la facilidad de uso de la aplicación.

15. Contenido perceptible, operable, comprensible y robusto: Puntuación personal acerca de la perceptibilidad, la operabilidad, la comprensibilidad y la robustez del contenido en la aplicación (Trato en el punto 5).

Podemos observar que en las 3 últimas variables la valoración es una opinión personal, el sistema es subjetivo, pero es sencillo y nos puede ayudar a tener una visión general de la aplicación en esos aspectos. Esta puntuación se llevará a cabo de 1 a 5 puntos, tal como se valora las propias aplicaciones por los usuarios en la tienda de aplicaciones.

\section{Resultado del análisis y conclusiones}

Una vez analizadas las 20 aplicaciones móviles (anexos I, II y III) teniendo en cuenta los factores comentados anteriormente nos dispondremos a especificar los resultados de dicho análisis:

$1^{\circ}$ Respecto el tipo de destino nos encontramos con que la mayoría se refieren a ciudades o localidades, concretamente el 75\%, seguido de lejos por comunidades autónomas con un 15\% y llama la atención el bajo porcentaje de solo un $10 \%$ de provincias. Esto puede interpretarse como la falta de apoyo turístico que existe entre las localidades de una misma zona. $2^{\circ}$ En lo que concierne al precio de aplicaciones vemos como el $75 \%$ de ellas son totalmente gratuitas y sin publicidad, lo cual facilita la descarga y la navegación por parte del usuario. El $20 \%$ son gratuitas, pero tratan de aprovechar la publicidad en la aplicación para ganar beneficio. De las 20 aplicaciones solo existe una aplicación que es de pago. Confirmamos por tanto dichas aplicaciones móviles de destinos turísticos como medios de comunicación para mejorar generar notoriedad e interés en el turista y no como modelo de generar beneficio económico.

$3^{\circ}$ En el tamaño de las aplicaciones la media es de 80 MB por aplicación, pasando de aplicaciones bastante pequeñas de $4 \mathrm{MB}$ hasta la mayor de 324 MB. En resumen, encontramos el tamaño adecuado, más teniendo en cuenta la creciente capacidad de los Smartphones.

$4^{\circ}$ En lo que respecta a la actualización de las aplicaciones vemos que sólo el $30 \%$ de ellas se han actualizado en el año 2015, el 35\% durante el año 2014 y otro 35\% tuvieron su última actualización durante el año 2013 o un año anterior. Llama la atención el alto porcentaje de aplicaciones que llevan tiempo sin actualizarse, teniendo además en cuenta la salida de nuevos sistemas operativos que pueden agilizar y mejorar la propia aplicación. 
$5^{\circ}$ La valoración de los idiomas disponibles en las diferentes aplicaciones es excelente, prácticamente todas las aplicaciones poseen al menos 2 idiomas, el 35\% lleva incorporado 3 idiomas y el 60\% están disponibles en 4 o más idiomas, lo que hace resaltar la importancia del turismo internacional a nuestro país y la necesidad de adaptar el producto a dichos turistas.

$6^{\circ}$ Respecto a la oficialidad comprobamos que el $80 \%$ de las aplicaciones no son oficiales o no pertenecen a algún estamento público. Esto no hace más que denotar la falta de confianza que siguen teniendo estos estamentos públicos a las nuevas tecnologías.

$7^{\circ}$ En lo que se refiere a la puntuación de los usuarios en las tiendas de aplicaciones tenemos otra notable valoración. Aunque hay tres aplicaciones que no tienen valoración, la media de valoraciones por parte de los usuarios es de 30 por aplicación, además la puntuación (del 1 al 5) es muy alta contemplándose una media de 4,5 entre las aplicaciones que se han valorado. Podemos considerar que el usuario agradece y colabora cuando se le satisface adecuadamente y tiene una buena experiencia con dicha aplicación.

$8^{\circ}$ En la existencia de sitio Web para la aplicación nos encontramos que el $65 \%$ de las aplicaciones tienen o aparecen en un sitio Web. Podemos considerar esta valoración baja teniendo en cuenta la importancia de tener todos los elementos digitales interrelacionados.

$9^{\circ}$ Lo mismo sucede con la conectividad en las redes sociales, en el que solo el $40 \%$ de las aplicaciones móviles posibilitan el acceso a las principales redes sociales.

$10^{\circ}$ Otro punto a mejorar sería el de la interactividad, el $75 \%$ de las aplicaciones analizadas tiene una interactividad bastante baja, por lo cual no permite al usuario intervenir en la propia aplicación o tener un papel activo en la generación de contenido.

$11^{\circ}$ En lo que respecta a las funciones hemos identificado 10 principales, haremos un resumen identificando las funciones y que tanto por ciento sí se encuentran o no en las aplicaciones analizadas:

- Geolocalización: Sí 65\% No 35\%

- Realidad aumentada: Sí 25\% No 75\%

- Oferta turística en el destino: Todas las aplicaciones ofrecen una oferta turística complementaria sobre todo basada en hoteles, restaurantes y ocio.

- Contenido multimedia: Sí (fotos) $80 \%$ No $20 \%$

- Contenido offline: La totalidad de las aplicaciones pueden ejecutarse sin conexión a internet.

- Agenda: Sí 55\% No 45\%

- Itinerario o ruta: Sí $45 \%$ No 55\%

- Buscador: Sí 50\% No 50\%

- Audioguía: Sí 25\% No 75\%

- Promociones: Sí 30\% No 70\% 
De las funciones de las aplicaciones podemos concluir que hay mucha diversidad y que esta está muy repartida entre las diferentes aplicaciones, no obstante, se considera en líneas generales que las aplicaciones no aprovechan del todo las posibilidades de las que dispone para dirigirse al usuario, entre las que destacan la baja inclusión de aspectos tan importantes como la geolocalización, realidad aumentada o promociones. Por el contrario, existe un buen aprovechamiento del contenido multimedia referido a las imágenes y de las ofertas turísticas disponibles en el destino turístico, sobre todo hoteles, restaurantes y ocio.

$12^{\circ}$ Vemos como solo el $15 \%$ de las aplicaciones hacen alguna mención a la accesibilidad de personas discapacitadas y solo una lo hace de manera directa, desarrollando información acerca del turismo accesible y sostenible.

$13^{\circ}$ Por último haremos un resumen de los 3 últimos puntos referidos a una puntuación personal de aspectos como el atractivo del contenido, el diseño y la usabilidad (del 1 al 5):

Puntuación diseño: 3,15

Puntuación usabilidad: 3,4

Puntuación contenido accesible: 3,2

Vemos que la valoración es bastante pareja, estando a un nivel aceptable cada uno de los tres términos, destacando un poco más la usabilidad por el fácil acceso y uso de las aplicaciones. 
Anexo I. Análisis de aplicaciones móviles de los destinos turísticos de Valencia, Mallorca, Aragón, Asturias, Barcelona (Guía Oficial), Madrid Valladolid.

\begin{tabular}{|c|c|c|c|c|c|c|c|}
\hline $\begin{array}{l}\text { Nombre } \\
\text { de la } \\
\text { aplicación }\end{array}$ & $\begin{array}{l}\text { Now } \\
\text { Valencia } \\
\text { - Guía de } \\
\text { Valencia, } \\
\text { Agenda, } \\
\text { Eventos }\end{array}$ & $\begin{array}{l}\text { Mallorca } \\
\text { RunAway } \\
\text { Guide }\end{array}$ & $\begin{array}{l}\text { Aragón- } \\
\text { Guía de } \\
\text { viajes }\end{array}$ & $\begin{array}{l}\text { Guía } \\
\text { turística de } \\
\text { Asturias }\end{array}$ & $\begin{array}{l}\text { Barcelona } \\
\text { Guía } \\
\text { oficial }\end{array}$ & $\begin{array}{l}\text { Madrid } \\
360^{\circ}\end{array}$ & $\begin{array}{l}\text { Turismo } \\
\text { Valladolid }\end{array}$ \\
\hline $\begin{array}{l}\text { Destino } \\
\text { turístico }\end{array}$ & Valencia & Mallorca & Aragón & Asturias & Barcelona & Madrid & Valladolid \\
\hline $\begin{array}{l}\text { Tipo de } \\
\text { destino }\end{array}$ & Ciudad & Isla & $\begin{array}{l}\text { Comunidad } \\
\text { Autónoma }\end{array}$ & $\begin{array}{l}\text { Comunidad } \\
\text { Autónoma }\end{array}$ & Ciudad & Ciudad & Ciudad \\
\hline Precio & Gratis & $\begin{array}{l}\text { Gratis con } \\
\text { publicidad }\end{array}$ & Gratis & $\begin{array}{l}\text { Gratis con } \\
\text { publicidad }\end{array}$ & Gratis & Gratis & Gratis \\
\hline Tamaño & $22,7 \mathrm{MB}$ & $324 M B$ & $38,9 \mathrm{MB}$ & $29,8 \mathrm{MB}$ & $62,4 \mathrm{MB}$ & $204 \mathrm{MB}$ & $4,7 \mathrm{MB}$ \\
\hline $\begin{array}{l}\text { Última } \\
\text { actualización }\end{array}$ & $6 / 8 / 14$ & $22 / 10 / 14$ & $10 / 12 / 13$ & $13 / 3 / 14$ & $29 / 4 / 15$ & $14 / 2 / 13$ & $29 / 1 / 11$ \\
\hline Idiomas & $\begin{array}{l}\text { Español, } \\
\text { inglés y } \\
\text { alemán }\end{array}$ & $\begin{array}{l}\text { Español, } \\
\text { inglés, } \\
\text { alemán, } \\
\text { catalán, } \\
\text { francés, } \\
\text { italiano, } \\
\text { japonés, } \\
\text { noruego, } \\
\text { portugués } \\
\text { y ruso }\end{array}$ & $\begin{array}{l}\text { Español, } \\
\text { alemán, } \\
\text { catalán, } \\
\text { francés, } \\
\text { inglés, } \\
\text { italiano, } \\
\text { japonés y } \\
\text { portugués }\end{array}$ & $\begin{array}{l}\text { Español e } \\
\text { inglés }\end{array}$ & $\begin{array}{l}\text { Español, } \\
\text { Alemán, } \\
\text { Bokmål, } \\
\text { noruego, } \\
\text { Danés, } \\
\text { Francés, } \\
\text { Griego, } \\
\text { Indonesio, } \\
\text { Inglés, } \\
\text { Italiano, } \\
\text { Neer- } \\
\text { landés, } \\
\text { Noruego } \\
\text { nynorsk }\end{array}$ & $\begin{array}{l}\text { Español, } \\
\text { inglés y } \\
\text { alemán }\end{array}$ & $\begin{array}{l}\text { Español, } \\
\text { inglés y } \\
\text { francés }\end{array}$ \\
\hline Oficialidad & No & No & No & No & Sí & No & Sí \\
\hline $\begin{array}{l}\text { Puntuación } \\
\text { de usuarios } \\
\text { en tienda }\end{array}$ & $\begin{array}{l}4,5^{*}(121 \\
\text { valoracio- } \\
\text { nes })\end{array}$ & $\begin{array}{l}5^{*}(17 \text { va- } \\
\text { loraciones) }\end{array}$ & No hay & $\begin{array}{l}3,5^{*} \text { (8 valo } \\
\text { raciones) }\end{array}$ & $\begin{array}{l}4,5^{*}(15 \\
\text { valoracio- } \\
\text { nes })\end{array}$ & $\begin{array}{l}3,5^{*}(51 \\
\text { valoracio- } \\
\text { nes })\end{array}$ & $\begin{array}{l}4,5^{*}(7 \\
\text { valoracio- } \\
\text { nes) }\end{array}$ \\
\hline $\begin{array}{l}\text { Tiene sitio } \\
\text { Web }\end{array}$ & Sí & Sí & No & Sí & Sí & Sí & No \\
\hline $\begin{array}{l}\text { Conectividad } \\
\text { con RRSS }\end{array}$ & No & No & No & No & No & Sí & No \\
\hline Interactividad & Baja & $\begin{array}{l}\text { Alta } \\
\text { (Permite } \\
\text { importar } \\
\text { imágenes, } \\
\text { tomar una } \\
\text { foto, dejar } \\
\text { un mensa- } \\
\text { je y hacer } \\
\text { check in) }\end{array}$ & Baja & Baja & Baja & Baja & Baja \\
\hline $\begin{array}{l}\text { Geolo- } \\
\text { calización }\end{array}$ & Sí & Sí & Sí & Sí & No & Sí & No \\
\hline $\begin{array}{l}\text { Realidad } \\
\text { aumentada }\end{array}$ & No & Sí & No & No & No & No & No \\
\hline
\end{tabular}


20 Análisis de las aplicaciones móviles de destinos turísticos y su accesabilidad.

Miguel Ángel Sánchez Jiménez, Rafael Ravina Ripoll

\begin{tabular}{|c|c|c|c|c|c|c|c|}
\hline $\begin{array}{l}\text { Otra oferta } \\
\text { turística en el } \\
\text { destino }\end{array}$ & $\begin{array}{l}\text { Sí ( hos- } \\
\text { telería, } \\
\text { ocio, vida } \\
\text { nocturna } \\
\text { y com- } \\
\text { pras) }\end{array}$ & $\begin{array}{l}\text { Sí ( hos- } \\
\text { telería, } \\
\text { compras, } \\
\text { transporte } \\
\text { y qué } \\
\text { hacer }\end{array}$ & $\begin{array}{l}\text { Sí ( hostel- } \\
\text { ería) }\end{array}$ & $\begin{array}{l}\text { Sí ( hostel- } \\
\text { ería, ocio } \\
\text { y aventura } \\
\text { y vida noc- } \\
\text { turna) }\end{array}$ & $\begin{array}{l}\text { Sí (hoste- } \\
\text { lería, ocio } \\
\text { y comer- } \\
\text { cio) }\end{array}$ & No & No \\
\hline $\begin{array}{l}\text { Recursos } \\
\text { Multimedia }\end{array}$ & Sí (fotos) & Sí (fotos) & Sí (fotos) & Sí (fotos) & Sí (fotos) & No & No \\
\hline $\begin{array}{l}\text { Contenido } \\
\text { Offline }\end{array}$ & Sí & Sí & Sí & Sí & Sí & Sí & Sí \\
\hline Agenda & No & Sí & No & No & No & No & No \\
\hline $\begin{array}{l}\text { Itinerario o } \\
\text { rutas }\end{array}$ & No & Sí & Sí & Sí & Sí & $\mathrm{Si}$ & Sí \\
\hline Buscador & Sí & Sí & No & No & Sí & Sí & No \\
\hline $\begin{array}{l}\text { Audio o vid- } \\
\text { eoguia }\end{array}$ & No & No & No & No & No & No & No \\
\hline Promociones & Sí & Sí & No & No & No & No & No \\
\hline $\begin{array}{l}\text { Accesibilidad } \\
\text { para disca- } \\
\text { pacitados }\end{array}$ & No & No & No & No & $\begin{array}{l}\text { Sí (espacio } \\
\text { dedicado } \\
\text { al turismo } \\
\text { accesible y } \\
\text { sostenible) }\end{array}$ & No & No \\
\hline $\begin{array}{l}\text { Puntuación } \\
\text { diseño }\end{array}$ & $4^{*}$ & $5^{*}$ & $2^{*}$ & $1^{*}$ & $4^{*}$ & $1^{*}$ & $1^{*}$ \\
\hline $\begin{array}{l}\text { Puntuación } \\
\text { usabilidad }\end{array}$ & $5^{*}$ & $4^{*}$ & $2^{*}$ & $3^{*}$ & $3^{*}$ & $3^{*}$ & $1^{*}$ \\
\hline $\begin{array}{l}\text { Puntuación } \\
\text { contenido } \\
\text { perceptible, } \\
\text { operable, } \\
\text { comprensible } \\
\text { y robusto }\end{array}$ & $5^{*}$ & $5^{*}$ & $2^{*}$ & $3^{*}$ & $3^{*}$ & $2^{*}$ & $1^{*}$ \\
\hline
\end{tabular}


Anexo II. Análisis de aplicaciones móviles de los destinos turísticos de Euskadi, Alicante, Toledo, Granada, Barcelona (audio guía turística), Jerez de la Frontera y Talavera.

\begin{tabular}{|c|c|c|c|c|c|c|c|}
\hline $\begin{array}{l}\text { Nombre de } \\
\text { la aplicación }\end{array}$ & $\begin{array}{l}\text { Now } \\
\text { Valencia } \\
\text { - Guía de } \\
\text { Valencia, } \\
\text { Agenda, } \\
\text { Eventos }\end{array}$ & $\begin{array}{l}\text { Mallorca } \\
\text { RunAway } \\
\text { Guide }\end{array}$ & $\begin{array}{l}\text { Aragón - } \\
\text { Guía de } \\
\text { viajes }\end{array}$ & $\begin{array}{l}\text { Guía } \\
\text { turística de } \\
\text { Asturias }\end{array}$ & $\begin{array}{l}\text { Barcelona } \\
\text { Guía oficial }\end{array}$ & $\begin{array}{l}\text { Madrid } \\
360^{\circ}\end{array}$ & $\begin{array}{l}\text { Turismo } \\
\text { Valladolid }\end{array}$ \\
\hline $\begin{array}{l}\text { Destino } \\
\text { turístico }\end{array}$ & Valencia & Mallorca & Aragón & Asturias & Barcelona & Madrid & Valladolid \\
\hline $\begin{array}{l}\text { Tipo de des- } \\
\text { tino }\end{array}$ & $\begin{array}{l}\text { Comu- } \\
\text { nidad } \\
\text { Autónoma }\end{array}$ & Ciudad & Ciudad & Ciudad & Ciudad & Ciudad & Ciudad \\
\hline Precio & $\begin{array}{l}\text { Gratis } \\
\text { con publi- } \\
\text { cidad }\end{array}$ & Gratis & Gratis & Gratis & $\begin{array}{l}\text { De pago } \\
(3,99 \mathrm{E})\end{array}$ & $\begin{array}{l}\text { Gratis } \\
\text { con pu- } \\
\text { blicidad }\end{array}$ & Gratis \\
\hline Tamaño & $126 \mathrm{MB}$ & $20.6 \mathrm{MB}$ & $29.4 \mathrm{MB}$ & $28.7 \mathrm{MB}$ & $83.3 \mathrm{MB}$ & $6.7 \mathrm{MB}$ & 19.7 MB \\
\hline $\begin{array}{l}\text { Última } \\
\text { actualización }\end{array}$ & $27 / 9 / 14$ & $29 / 7 / 14$ & $13 / 2 / 14$ & $22 / 2 / 13$ & $11 / 3 / 13$ & $2 / 4 / 14$ & $6 / 1 / 11$ \\
\hline Idiomas & $\begin{array}{l}\text { Español, } \\
\text { inglés y } \\
\text { francés }\end{array}$ & $\begin{array}{l}\text { Español e } \\
\text { inglés }\end{array}$ & $\begin{array}{l}\text { Español, } \\
\text { Alemán, } \\
\text { Francés, } \\
\text { Inglés, } \\
\text { Italiano, } \\
\text { Japonés }\end{array}$ & Español & $\begin{array}{l}\text { Español, } \\
\text { Alemán, } \\
\text { Francés, } \\
\text { Inglés, } \\
\text { Italiano, } \\
\text { Japonés }\end{array}$ & $\begin{array}{l}\text { Español, } \\
\text { inglés y } \\
\text { alemán }\end{array}$ & $\begin{array}{l}\text { Español e } \\
\text { Inglés }\end{array}$ \\
\hline Oficialidad & No & No & No & No & No & No & No \\
\hline $\begin{array}{l}\text { Puntuación } \\
\text { de usuarios } \\
\text { en tienda }\end{array}$ & $\begin{array}{l}5^{*}(9 \\
\text { valoracio- } \\
\text { nes })\end{array}$ & $\begin{array}{l}3,5 \text { ( } 38 \\
\text { valoracio- } \\
\text { nes) }\end{array}$ & $\begin{array}{l}4,5^{*}(34 \\
\text { valoracio- } \\
\text { nes) }\end{array}$ & $\begin{array}{l}4^{*}(5 \text { valor- } \\
\text { aciones) }\end{array}$ & $\begin{array}{l}4,5+(42 \\
\text { valoracio- } \\
\text { nes })\end{array}$ & $\begin{array}{l}5^{*}(8 \\
\text { valora } \\
\text { ciones })\end{array}$ & $\begin{array}{l}4,5^{*}(7 \\
\text { valoracio- } \\
\text { nes })\end{array}$ \\
\hline $\begin{array}{l}\text { Tiene } \\
\text { sitio Web }\end{array}$ & Sí & Sí & Sí & No & No & No & \\
\hline \multirow[t]{2}{*}{ No } & No & No & No & No & No & Sí & No \\
\hline & Baja & $\begin{array}{l}\text { Alta } \\
\text { (Permite } \\
\text { importar } \\
\text { imágenes, } \\
\text { tomar una } \\
\text { foto, dejar } \\
\text { un mensaje } \\
\text { y hacer } \\
\text { check in) }\end{array}$ & Baja & Baja & Baja & Baja & Baja \\
\hline $\begin{array}{l}\text { Conectividad } \\
\text { con RRSS }\end{array}$ & No & No & Sí & No & No & Sí & No \\
\hline
\end{tabular}




\begin{tabular}{|c|c|c|c|c|c|c|c|}
\hline $\begin{array}{l}\text { Interactivi- } \\
\text { dad }\end{array}$ & $\begin{array}{l}\text { Alta } \\
\text { (Permite } \\
\text { importar } \\
\text { imá- } \\
\text { genes, } \\
\text { tomar } \\
\text { una foto, } \\
\text { dejar un } \\
\text { mensaje } \\
\text { y hacer } \\
\text { check in) }\end{array}$ & Baja & $\begin{array}{l}\text { Media } \\
\text { (se puede } \\
\text { votar) }\end{array}$ & Baja & Baja & Baja & Baja \\
\hline $\begin{array}{l}\text { Geoloca- } \\
\text { lización }\end{array}$ & Sí & oo & Sí & No & Sí & No & No \\
\hline $\begin{array}{l}\text { Realidad } \\
\text { aumentada }\end{array}$ & Sí & No & Sí & No & No & No & No \\
\hline $\begin{array}{l}\text { Otra oferta } \\
\text { turística en } \\
\text { el destino }\end{array}$ & $\begin{array}{l}\text { Sí (hos- } \\
\text { telería, } \\
\text { compras, } \\
\text { trans- } \\
\text { porte y } \\
\text { qué hacer }\end{array}$ & $\begin{array}{l}\text { Sí (hos- } \\
\text { telería, } \\
\text { ocio, vida } \\
\text { nocturna, } \\
\text { compras } \\
\text { y mar) }\end{array}$ & $\begin{array}{l}\text { Sí } \\
\text { (hoste- } \\
\text { lería, vida } \\
\text { nocturna } \\
\text { y ocio) }\end{array}$ & $\begin{array}{l}\text { Sí } \\
\text { (hostelería, } \\
\text { ocio y } \\
\text { compras) }\end{array}$ & No & $\begin{array}{l}\text { Sí } \\
\text { (hos- } \\
\text { telería, } \\
\text { compras } \\
\text { y ocio) }\end{array}$ & $\begin{array}{l}\text { Sí } \\
\text { (hoste- } \\
\text { lería) }\end{array}$ \\
\hline $\begin{array}{l}\text { Recursos } \\
\text { Multimedia }\end{array}$ & Sí (fotos) & Sí (fotos) & Sí (fotos) & Sí (fotos) & No & Sí (fotos) & No \\
\hline $\begin{array}{l}\text { Contenido } \\
\text { Offline }\end{array}$ & Sí & Sí & Sí & Sí & Sí & Sí & Sí \\
\hline Agenda & Sí & No & Sí & Sí & No & No & Sí \\
\hline $\begin{array}{l}\text { Itinerario o } \\
\text { rutas }\end{array}$ & Sí & No & No & No & No & No & No \\
\hline Buscador & Sí & Sí & Sí & Sí & No & No & No \\
\hline $\begin{array}{l}\text { Audio o vid- } \\
\text { eoguia }\end{array}$ & No & No & $\begin{array}{l}\text { Sí (au- } \\
\text { dioguía) }\end{array}$ & No & $\begin{array}{l}\text { Sí (au- } \\
\text { dioguía) }\end{array}$ & $\begin{array}{l}\text { Sí (au- } \\
\text { dioguía) }\end{array}$ & No \\
\hline Promociones & Sí & Sí & No & Sí & No & Sí & No \\
\hline $\begin{array}{l}\text { Accesibilidad } \\
\text { para dis- } \\
\text { capacitados }\end{array}$ & No & No & No & No & No & No & No \\
\hline $\begin{array}{l}\text { Puntuación } \\
\text { diseño }\end{array}$ & $5^{*}$ & $4^{*}$ & $5^{*}$ & $3^{*}$ & $2^{*}$ & $1^{*}$ & $1^{*}$ \\
\hline $\begin{array}{l}\text { Puntuación } \\
\text { usabilidad }\end{array}$ & $4^{*}$ & $5^{*}$ & $5^{*}$ & $1^{*}$ & $3^{*}$ & $2^{*}$ & $3^{*}$ \\
\hline $\begin{array}{l}\text { Puntuación } \\
\text { contenido } \\
\text { perceptible, } \\
\text { operable, } \\
\text { comprensible } \\
\text { y robusto }\end{array}$ & $5^{*}$ & $5^{*}$ & $4^{*}$ & $2^{*}$ & $2^{*}$ & $3^{*}$ & $2^{*}$ \\
\hline
\end{tabular}


Anexo III. Análisis de aplicaciones móviles de los destinos turísticos de San Sebastián, Hondarribia, Gijón, Sanxexo, León y Conil de la Frontera.

\begin{tabular}{|c|c|c|c|c|c|c|}
\hline $\begin{array}{l}\text { Nombre de la } \\
\text { aplicación }\end{array}$ & $\begin{array}{l}\text { Be Your Guide } \\
\text { San Sebastián }\end{array}$ & $\begin{array}{l}\text { Hondarribia } \\
\text { Guía }\end{array}$ & $\begin{array}{l}\text { Gijón en el } \\
\text { bolsillo }\end{array}$ & $\begin{array}{l}\text { Guía de Sanx- } \\
\text { enxo Guía } \\
\text { Oficial }\end{array}$ & $\begin{array}{l}\text { Turismo en } \\
\text { León }\end{array}$ & $\begin{array}{l}\text { Be Your } \\
\text { Guide - Conil }\end{array}$ \\
\hline $\begin{array}{l}\text { Destino } \\
\text { turístico }\end{array}$ & $\begin{array}{l}\text { San } \\
\text { Sebastián }\end{array}$ & Hondarribia & Gijón & Sanxenxo & León & $\begin{array}{l}\text { Conil de la } \\
\text { Frontera }\end{array}$ \\
\hline $\begin{array}{l}\text { Tipo de } \\
\text { destino }\end{array}$ & Ciudad & Ciudad & Ciudad & Ciudad & Provincia & Ciudad \\
\hline Precio & Gratis & Gratis & Gratis & Gratis & Gratis & Gratis \\
\hline Tamaño & $75.9 \mathrm{MB}$ & $116 \mathrm{MB}$ & $73.8 \mathrm{MB}$ & $69.3 \mathrm{MB}$ & $20.93 \mathrm{MB}$ & $33.7 \mathrm{MB}$ \\
\hline $\begin{array}{l}\text { Última actual- } \\
\text { ización }\end{array}$ & $7 / 3 / 15$ & $10 / 7 / 13$ & $24 / 3 / 15$ & $19 / 3 / 15$ & $5 / 5 / 15$ & $25 / 4 / 15$ \\
\hline Idiomas & $\begin{array}{l}\text { Español, } \\
\text { Alemán, } \\
\text { Francés, } \\
\text { Inglés, } \\
\text { Italiano } \\
\text { y Ruso }\end{array}$ & $\begin{array}{l}\text { Español, } \\
\text { Alemán e } \\
\text { Inglés }\end{array}$ & $\begin{array}{l}\text { Español, } \\
\text { Francés e } \\
\text { Inglés }\end{array}$ & $\begin{array}{l}\text { Español, } \\
\text { Alemán, } \\
\text { Francés, Gal- } \\
\text { lego, Inglés e } \\
\text { Italiano }\end{array}$ & $\begin{array}{l}\text { Español, } \\
\text { Inglés y } \\
\text { Gallego }\end{array}$ & $\begin{array}{l}\text { Español, } \\
\text { Alemán, } \\
\text { Francés, } \\
\text { Inglés, Ruso } \\
\text { y Sueco }\end{array}$ \\
\hline Oficialidad & No & No & No & Sí & Sí & No \\
\hline $\begin{array}{l}\text { Puntuación de } \\
\text { usuarios en } \\
\text { tienda }\end{array}$ & $\begin{array}{l}5^{*}(25 \\
\text { valoraciones) }\end{array}$ & $\begin{array}{l}5^{*} \text { (6 valo- } \\
\text { raciones) }\end{array}$ & $\begin{array}{l}5^{*} \text { ( } 5 \text { valo- } \\
\text { raciones) }\end{array}$ & No hay & No hay & $\begin{array}{l}5^{*}(21 \text { va- } \\
\text { loraciones) }\end{array}$ \\
\hline Tiene sitio Web & Sí & No & Sí & Sí & Sí & Sí \\
\hline $\begin{array}{l}\text { Conectividad } \\
\text { con RRSS }\end{array}$ & Sí & Sí & Sí & Sí & No & Sí \\
\hline Interactividad & $\begin{array}{l}\text { Media } \\
\text { (se puede } \\
\text { votar) }\end{array}$ & Baja & Baja & Baja & Baja & $\begin{array}{l}\text { Media } \\
\text { (se puede } \\
\text { votar) }\end{array}$ \\
\hline Geolocalización & Sí & No & Sí & No & Sí & Sí \\
\hline $\begin{array}{l}\text { Realidad au- } \\
\text { mentada }\end{array}$ & Sí & No & No & No & No & Sí \\
\hline $\begin{array}{l}\text { Otra oferta } \\
\text { turística en el } \\
\text { destino }\end{array}$ & $\begin{array}{l}\text { Sí (hoste- } \\
\text { lería, vida noc- } \\
\text { turna y ocio) }\end{array}$ & $\begin{array}{l}\text { Sí (hostel- } \\
\text { ería, ocio } \\
\text { y aparca- } \\
\text { miento) }\end{array}$ & $\begin{array}{l}\text { Sí } \\
\text { (hostelería, } \\
\text { ocio y } \\
\text { playas) }\end{array}$ & $\begin{array}{l}\text { Sí } \\
\text { (hostelería } \\
\text { y ocio) }\end{array}$ & $\begin{array}{l}\text { Sí } \\
\text { (hostelería } \\
\text { y ocio) }\end{array}$ & $\begin{array}{l}\text { Sí (hoste- } \\
\text { lería, vida } \\
\text { nocturna } \\
\text { y ocio) }\end{array}$ \\
\hline $\begin{array}{l}\text { Recursos } \\
\text { Multimedia }\end{array}$ & $\begin{array}{l}\text { Sí } \\
\text { (fotos) }\end{array}$ & $\begin{array}{l}\text { Sí } \\
\text { (fotos) }\end{array}$ & $\begin{array}{l}\text { Sí } \\
\text { (fotos) }\end{array}$ & $\begin{array}{l}\text { Sí } \\
\text { (fotos) }\end{array}$ & $\begin{array}{l}\text { Sí } \\
\text { (fotos) }\end{array}$ & $\begin{array}{l}\text { Sí } \\
\text { (fotos) }\end{array}$ \\
\hline $\begin{array}{l}\text { Contenido } \\
\text { Offline }\end{array}$ & Sí & Sí & Sí & Sí & Sí & SI \\
\hline Agenda & Sí & Sí & Sí & Sí & Sí & Sí \\
\hline $\begin{array}{l}\text { Itinerario } \\
\text { o rutas }\end{array}$ & No & Sí & Sí & No & No & No \\
\hline Buscador & Sí & No & No & No & No & Sí \\
\hline $\begin{array}{l}\text { Audio o } \\
\text { videoguia }\end{array}$ & No & $\begin{array}{l}\text { Sí } \\
\text { (audioguía) }\end{array}$ & No & No & $\begin{array}{l}\text { Sí } \\
\text { (audioguía) }\end{array}$ & No \\
\hline
\end{tabular}




\begin{tabular}{lllllll}
\hline Promociones & No & No & No & No & No & No \\
\hline $\begin{array}{l}\text { Accesibilidad } \\
\text { para discapa- } \\
\text { citados }\end{array}$ & No & No & No & $\begin{array}{l}\text { Sí (infor- } \\
\text { mación sobre } \\
\text { atención } \\
\text { sanitaria y } \\
\text { farmacias) }\end{array}$ & $\begin{array}{l}\text { Sí (infor- } \\
\text { mación } \\
\text { sobre } \\
\text { atención } \\
\text { sanitaria y } \\
\text { farmacias) }\end{array}$ \\
\hline $\begin{array}{l}\text { Puntuación } \\
\text { diseño }\end{array}$ & $5^{*}$ & & & $2^{*}$ & $3^{*}$ & $5^{*}$ \\
\hline $\begin{array}{l}\text { Puntuación } \\
\text { usabilidad }\end{array}$ & $5^{*}$ & $4^{*}$ & $5^{*}$ & $2^{*}$ & $3^{*}$ & $4^{*}$ \\
\hline $\begin{array}{l}\text { Puntuación } \\
\text { contenido } \\
\text { perceptible, } \\
\text { operable, } \\
\text { comprensible } \\
\text { y robusto }\end{array}$ & $4^{*}$ & $5^{*}$ & $5^{*}$ & $2^{*}$ & $2^{*}$ & \\
\hline
\end{tabular}

\section{Bibliografía}

Allés, M. T. F. (2009). Turismo accesible y turismo para todos en España: antecedentes, estado de la cuestión y líneas de investigación. Estudios turísticos, (180), 141-154.

Bigné, J. E., Alcañiz, J. E. B., Aulet, X. F., \&Simó, L. A. (2000). Marketing de destinos turísticos: análisis y estrategias de desarrollo. Esic editorial.

Bruno Ramos. (2014). ASO, el único camino hacia el éxito de tu App. Diciembre, 15, 2014, de Increnta

Cuello, J., \& Vittone, J. (2013). Diseñando apps para móviles. José Vittone-Javier Cuello.

Delía, L., Galdámez, N., Thomas, P. J., \& Pesado, P. (2013). Un análisis experimental tipo de aplicaciones para dispositivos móviles. In XVIII Congreso Argentino de Ciencias de la Computación.

Estrade, J. M., Jordán, D., \& Hernández, M. A. (2013). Marketing Digital. Marketing móvil, SEO y analítica web.

González, Gil (2013). “Cómo hacer apps accesibles”. Disponible el 15 de marzo de 2015en:http://www.ceapat.es/InterPresent1/groups/imserso/documents/ binario/appsaccesibles.pdf

Hassan Montero, Y., \& Martín Fernández, F. J. (2003). Qué es la accesibilidad web. No Solo Usabilidad, (2).

Hassan, Y., Martín Fernández, F. J., \& lazza, G. (2004). Diseño web centrado en el usuario: usabilidad y arquitectura de la información. Hipertext. net, (2).

Henry, Shawn Lawton (2003). Another -ability: Accessibility Primer for Usability Specialists. UPA (Usability Professionals’ Association) 2003 Conference. Disponible el 25 de abril de 2015 en: Hernández, J. (2014). “Mobile Marketing”. Publixed, Madrid.

IAB Spain (2014). "VI Estudio Anual del Mobile Marketing”. 
Kim, J., Kim, C., Park, Y., \& Lee, H. (2012). Trends and relationships of smartphone application services: Analysis of Apple App Store using text mining-based network analysis. In Proceedings in the 4th ISPIM Innovation Symposium, Wellington, New Zealand.

Lara-Navarra, P., Serradell, E., \& Maniega, D. (2014). App, movilidad de contenidos para la extensión de servicios de información.

Liberos E, Núñez A, Bareño R, Rafael García del Poyo R, Juan Carlos Gutiérrez-Ulecia JC, Pino G. (2013). El libro del Marketing Interactivo y la Publicidad Digital. Madrid: ESIC EDITORIAL.

Manual de App Store Optimization ASO. (Septiembre, 2014) Manual de App Store Optimization [Aso] Diciembre, 15, 2014, de PickASO, Tribal WorldwideSpain e IAB Spain.

Martín, A., Gaetán, G., Saldaño, V. E., Pastrana, S., Miranda, G., \& Molina, S. (2012). Diseño y Evaluación tempranos para priorizar la Accesibilidad en la www. In XIV Workshop de Investigadores en Ciencias de la Computación.

Martín-Sánchez, M., Miguel-Dávila, J.A. \& López-Berzosa, D. (2012, octubre). M-tourism: las apps en el sector turístico. Ponencia en IX Congreso Nacional "Turismo y Tecnologías de la Información y las Comunicaciones”, TURITEC 2012, Málaga, España.

Melendo Rodríguez-Carmona, L. (2010). Aportaciones del teléfono móvil al marketing: situación y usos en España en el año 2009. Tesis Doctoral inédita, Universidad Camilo José Cela.

Mobile Marketing Association MMA. (2012) Libro Blanco de las web Móviles.

Mobile Marketing Association MMA. (2013). Conectando el mundo físico y el digital [guía MMA Spain] Disponible el 30 de mayo de 2015 en: http://www.mmaspain.com/

Montaner Barrio B (2013). Marketing Móvil basado en Aplicaciones Móviles. Trabajo académico inédito, Universidad de la Rioja.

Navarro, I., \& Fonseca, D. (2008). Accesibilidad Web en entornos culturales. In Proc. Conferencia CIAWI (pp. 583-585).

Nielsen, J., \& Loranger, H. (2006). Prioritizing web usability. Pearson Education.

Nielsen, Jakob. (2001). Beyond Accessibility: Treating People with Disabilities as People. Alertbox, 11 de Noviembre de 2001. Disponible el 27 de abril de 2015 en: Ortega, J. M. C. (2010). Smartphone: toda la información al alcance de tu mano. Telos: Cuadernos de comunicación e innovación, (83), 97-99.

Pérez, D. M., \& Velasco, D. J. G. (2003). Turismo accesible. Hacia un turismo para todos. Colección Comité Español de Representantes de Personas con Discapacidadceremi. es-. 111p.

Ramos, J. J. (2012). “Guía completa de mobile marketing”. Netizen.

Richardson, N. (2014). "Guía de acceso rápido al marketing móvil”. Granica, Madrid.

Rios, R., Garcia, E., Garcia-Cabot, A., de-Marcos, L., Oton, S., Gutiérrez-de-Mesa, R. B., \& Bar-Magen, J. (2012). Accesibilidad en Smartphones para el acceso a contenidos e-learning. In III Congreso Iberoamericano sobre Calidad y Accesibilidad de la Formación Virtual (CAFVIR 2012).

Rovira-Beleta (2005). La Accesibilidad. Disponible el 8 de marzo de 2015 en: www. RoviraBeleta.com 
Sánchez, C. C. (2012). Ciberperiodismo en el smartphone. Estudio de la multimedialidad, usabilidad, hipertextualidad e interactividad de las aplicaciones de medios nativos digitales para smartphone. Estudios sobre el mensaje periodístico, 18, 243-251.

Segitur (2013). Estudio de Mercado de Apps Turísticas. Disponible el 3 de marzo de 2015en:http://www.segittur.es/opencms/export/sites/segitur/.content/ galerias/descargas/documentos/Segittur_APPS-Turismo.pdf

Serrano Mascaraque, E., Moratilla Ocaña, A., \& Olmeda Martos, I. (2009). Directrices técnicas referidas a la accesibilidad Web.

The app date. (2014). $5^{\circ}$ Informe estado de las apps en España. Disponible el 30 de abril de 2015 en: http://www.theappdate.es/v-informe-estado-apps-espana/

Cavia, J.F. (Coord.) (2013). “Aplicaciones móviles de los destinos turísticos españoles”, Universidad Pompeu Fabra, Barcelona.

Vanderheiden, G. (2000). Fundamental Principles and Priority Setting for Universal Usability. En: Proceedings of Conference on Universal Usability (CUU) 2000, Association for Computing Machinery, pp32-38.

Vázquez, N. A. (2013). Desarrollo de aplicaciones móviles en bibliotecas. In VI Congreso Nacional de Bibliotecas públicas [Recurso electrónico]: memoria individual, patrimonio global (pp. 97-104). Ministerio de Educación, Cultura y Deporte.

Vision Mobile. (2014). How the app economy is creating jobs and driving growth in the EU. Diciembre, 15, 2014, de Vision Mobile.

W3C. “Web accessibility initiative”. Disponible el 20 de agosto de 2016 en: http://www. w3.org/WAl/mobile/

World Economic Forum (2015). “The Travel \& Tourism Competitiveness Report 2015”. Disponible el 14 de mayo de 2015 en: http://ep00.epimg.net/descargables/2015/05/06/ f2c1e517ce56a6453171d3a9d1b1da05.pdf 